\title{
In rabbits, landiolol, a new ultra-short-acting ß-blocker, exerts a more potent negative chronotropic effect and less effect on blood pressure than esmolol
}

[Le landiolol, un nouveau $\beta$-bloquant à action très brève, a un effet chronotropic négatif plus puissant et agit moins sur la tension artérielle que l'esmolol chez le lapin]

Junichi Sasao MD, ${ }^{*}$ Stephen D. Tarver MD, ${ }^{*}$ James D. Kindscher MD, ${ }^{*}$ Chikuni Taneyama MD,$\dagger$ Kirk T. Benson MD, ${ }^{*}$ Hiroshi Goto MD*

Purpose: To compare the cardiovascular and sympathetic effects of a new ultra-short-acting, highly cardioselective ß- blocker, landiolol, with esmolol, using an in vivo rabbit model.

Methods: Different bolus doses of landiolol (0.3, I.0, 3.0 and 10.0 $\left.\mathrm{mg} \cdot \mathrm{kg}^{-1}\right)$ or esmolol $\left(0.5,1.5\right.$ and $\left.5.0 \mathrm{mg} \cdot \mathrm{kg}^{-1}\right)$ were given intravenously, and the effects on heart rate (HR) mean arterial pressure (MAP) and renal sympathetic nerve activity (RSNA) were compared.

Results: Both landiolol and esmolol produced a dose-dependent decrease in HR. The maximum percent reductions of HR were similar with landiolol $3 \mathrm{mg} \cdot \mathrm{kg}^{-1}$ and esmolol $5 \mathrm{mg} \cdot \mathrm{kg}^{-1}(-14.0 \pm$ $0.9 \%$ and $-13.9 \pm 1.4 \%$, mean $\pm \mathrm{SE}$, respectively). HR decreased more rapidly with landiolol than with esmolol. Esmolol produced a dose-dependent decrease in MAP that was not observed with landiolol. The percent maximum reduction of MAP was $-38.2 \pm$ $3.2 \%$ with esmolol $5 \mathrm{mg} \cdot \mathrm{kg}^{-1}$. RSNA increased in a dose-dependent fashion with esmolol, but no changes were noted with landiolol.

Conclusion: These results suggest that, in rabbits, landiolol has slightly more potent negative chronotropic action than esmolol with significantly less effects on blood pressure.

Objectif: Comparer les effets cardiovasculaires et sympathiques d'un nouveau B-bloquant à action très brève et hautement cardiosélectif, le landiolol, avec ceux de l'esmolol, en utilisant un modèle in vivo chez le lapin

Méthode : On a administré différents bolus intraveineux de landiolol $\left(0,3 ; 1,0 ; 3,0\right.$ et $\left.10,0 \mathrm{mg} \cdot \mathrm{kg}^{-1}\right)$ ou d'esmolol $(0,5 ; 1,5$ et 5,0 $\mathrm{mg} \cdot \mathrm{kg}^{-1}$ ) et comparé les effets sur la fréquence cardiaque (FC), la tension artérielle moyenne (TAM) et l'activité sympathique rénale (ASR). Résultats : Le landiolol et l'esmolol ont produit une baisse de la FC proportionnelle à la dose. Les réductions maximales de $F C$ ont été similaires avec $3 \mathrm{mg} \cdot \mathrm{kg}^{-1}$ de landiolol et $5 \mathrm{mg} \cdot \mathrm{kg}^{-1}$ d'esmolol (- $14,0 \pm$ $0,9 \%$ et $-13,9 \pm 1,4 \%$, moyenne \pm écart type, respectivement). La FC a baissé plus rapidement avec le landiolol qu'avec l'esmolol. L'esmolol, contrairement au landiolol, a produit une baisse de la TAM proportionnelle à la dose. La réduction maximale de TAM a été de $38,2 \pm 3,2 \%$ avec $5 \mathrm{mg} \cdot \mathrm{kg}^{-1}$ d'esmolol. L'ASR a augmenté selon la dose avec l'esmolol, mais aucun changement n'a été observé avec le landiolol.

Conclusion : Ces résultats suggèrent que, chez les lapins, le landiolol présente une action chronotropique négative plus puissante que l'esmolol et des effets significativement plus faibles sur la tension artérielle.

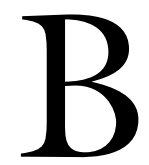

ETA blocking agents are used extensively for heir ability to attenuate the deleterious effects of excessive adrenergic stimulation with tachyarrhythmia. Esmolol has gained popularity in controlling tachycardia because of its ultra-short action and high cardioselectivity. ${ }^{1}$ However, with high doses, esmolol can be directly cardiodepressive and can cause hypotension, even congestive heart failure, thereby limiting its usefulness. ${ }^{2-5}$ Recently, landiolol was developed by altering the chemical structure

From the Department of Anesthesiology, ${ }^{*}$ University of Kansas Medical Center, Kansas City, Kansas, USA; and the Clinic of Taneyama, $†$ Shiojiri-shi, Japan.

Address correspondence to: Dr. Hiroshi Goto, Department of Anesthesiology, University of Kansas Medical Center, 3901 Rainbow Blvd., Kansas City, Kansas USA 66160-7415. Phone: 913-588-6670; Fax: 913-588-3365; E-mail: hgoto@kumc.edu

Accepted for publication June 5, 2001.

Revision accepted July 27, 2001. 
of esmolol to produce a greater degree of cardioselectivity and more potency as a $B$-adrenoceptor blocker without increasing the half- life. ${ }^{6}$ Early studies using landiolol have resulted in conflicting results in regard to its B-blocking potency in relation to esmolol. ${ }^{6-9}$ The purpose of this study was to compare the cardiovascular and sympathetic effects of landiolol with esmolol using a neuraxis intact rabbit model.

\section{Materials and methods}

The Institutional Animal Care and Use Committee approved this study and appropriate guidelines for the use of animals were observed throughout. In adult, male, New Zealand white rabbits, the ear vein was cannulated for induction of anesthesia. The animals were anesthetized by $i v$ administration of urethane (1 $\left.\mathrm{g} \cdot \mathrm{kg}^{-1}\right)$. Anesthesia was maintained with supplemental administration of iv urethane $\left(100 \mathrm{mg} \cdot \mathrm{kg}^{-1} \cdot \mathrm{hr}^{-1}\right)$ throughout the experiment. A tracheotomy was performed and the rabbits were ventilated with an infant ventilator, using oxygen in nitrogen at a tidal volume of $10-15 \mathrm{~mL} \cdot \mathrm{kg}^{-1}$ and a frequency of $25-30$ cycles. $\mathrm{min}^{-1}$. Polyethylene catheters were placed in the femoral vein for $i v$ administration of drugs, and in the femoral artery for measurement of arterial pressure and sampling of arterial blood. The animals were paralyzed with vecuronium $\left(0.1 \mathrm{mg} \cdot \mathrm{kg}^{-1} i \mathrm{v}\right)$ to avoid artifacts in the measurement of sympathetic nerve activity secondary to muscle movement. Acid-base balance was maintained within normal limits $\left(\mathrm{PaCO}_{2} 35-45\right.$ $\mathrm{mmHg}, \mathrm{pH} 7.35-7.45$ ) by adjusting the tidal volume and ventilatory rate. The $\mathrm{PaO}_{2}$ was maintained between 100 and $200 \mathrm{mmHg}$. Arterial blood pressure was recorded continuously. Mean arterial pressure (MAP) was derived by electronic integration of the pulsatile pressure signal. Heart rate (HR) was calculated from lead II of the electrocardiogram, using a cardiotachometer. Body temperature was maintained at more than $37 \mathrm{C}$ by external warming.

Recording of renal sympathetic nerve activity (RSNA) The details of measurement and recording of RSNA have been described elsewhere. ${ }^{10,11}$ Briefly, the left kidney was exposed retroperitoneally by a left flank incision. Renal sympathetic nerves along the renal artery were isolated using a microscope. The distal end of the strands were crushed, and the sympathetic nerves were immersed in mineral oil and placed on a bipolar silver electrode for recording the renal nerve discharges. The raw nerve signals were amplified. The amplified nerve discharges were visualized on a dualbeam oscilloscope and monitored by an audio speaker. An absolute value circuit rectified the raw nerve signals. RSNA was obtained by integrating the rectified signal with a time constant of $2.0 \mathrm{sec}$ using a resistance-capacitance integrator circuit.

Sixteen rabbits were randomly divided into two groups with the landiolol group $(n=8)$ receiving an $i v$ bolus of landiolol at $0.3,1.0,3.0$ and $10.0 \mathrm{mg} \cdot \mathrm{kg}^{-1}$, and the esmolol group $(n=8)$ receiving an $i v$ bolus of esmolol at $0.5,1.5$ and $5.0 \mathrm{mg} \cdot \mathrm{kg}^{-1}$. After completion of surgical preparation and hemodynamic stabilization, consecutively increasing doses of both agents were administered, with all variables returning to baseline values after each injection, and with at least a 20-min interval between the two bolus injections. HR, MAP and RSNA were recorded continuously and values before each bolus injection were defined as $100 \%$ control values for comparison.

All data were expressed as mean \pm SE. Statistical analysis was performed using repeated measure analysis of variance, followed by Duncan's new multiple range method. Differences with a statistical probability of less than 0.05 were considered significant.

\section{Results}

The time course of changes in HR after bolus injection of landiolol and esmolol are presented in Figure 1. HR returned to baseline values within five minutes after the first three doses of landiolol and the first two doses of esmolol. Landiolol produced a dose-related, fairly rapid reduction in HR. The maximum percent reduction of HR with $0.3,1.0,3.0$ and $10.0 \mathrm{mg} \cdot \mathrm{kg}^{-1}$ of landiolol were $-5.6 \pm 1.1,-9.9 \pm 1.0,-14.0 \pm 0.9$, and $-18.2 \pm$ $0.9 \%$ respectively. These were observed within one minute of the injection. Esmolol produced similar doserelated reductions in $\mathrm{HR}$, but the maximum reduction occurred after one minute of the injection. The maximum percent reductions of $\mathrm{HR}$ with $0.5,1.5$ and 5.0 $\mathrm{mg} \cdot \mathrm{kg}^{-1}$ of esmolol were $-6.9 \pm 0.6,-11.8 \pm 1.4$ and $13.9 \pm 1.4 \%$, respectively. Landiolol $\left(3.0 \mathrm{mg} \cdot \mathrm{kg}^{-1}\right)$ and esmolol $\left(5.0 \mathrm{mg} \cdot \mathrm{kg}^{-1}\right)$ produced approximately the same maximal HR reduction.

The time course of changes in MAP for both landiolol and esmolol are presented in Figure 2. MAP did not change significantly until $10 \mathrm{mg} \cdot \mathrm{kg}^{-1}$ landiolol was given $(-6.0 \pm 1.8 \%, P<0.05)$. On the other hand, esmolol caused a dose-dependent reduction in MAP. The maximum percent reduction of MAP with the highest dose of esmolol $\left(5.0 \mathrm{mg} \cdot \mathrm{kg}^{-1}\right)$ was $-38.2 \pm$ $3.2 \%$. The reduction in MAP with esmolol was shortlived, trending toward baseline after three minutes with even the highest dose. The RSNA did not significantly change with any of the landiolol bolus doses. Esmolol did result in a transient increase in RSNA that appears to be dose-dependent (Figure 3 ). 


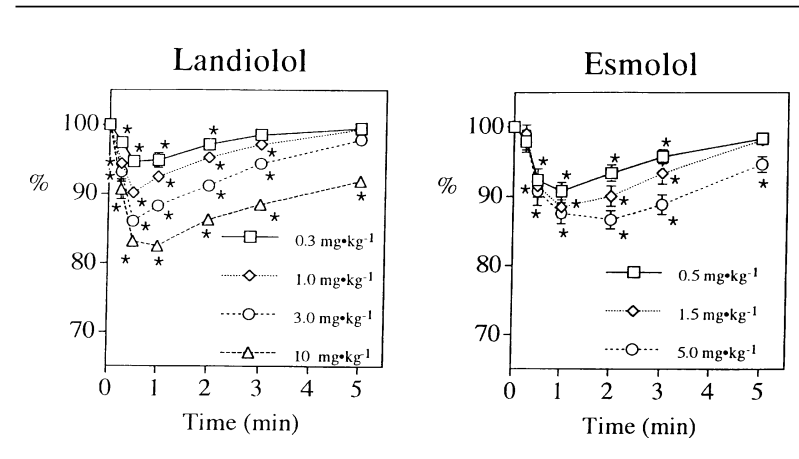

FIGURE 1 Time course of changes (\%) in heart rate (HR). Values are mean $\pm \operatorname{SE}(n=8) .{ }^{*} P<0.05$ vs baseline values. Note: HR decreased in a dose-dependent fashion with both agents. However, reduction of HR was more rapid with landiolol than with esmolol.
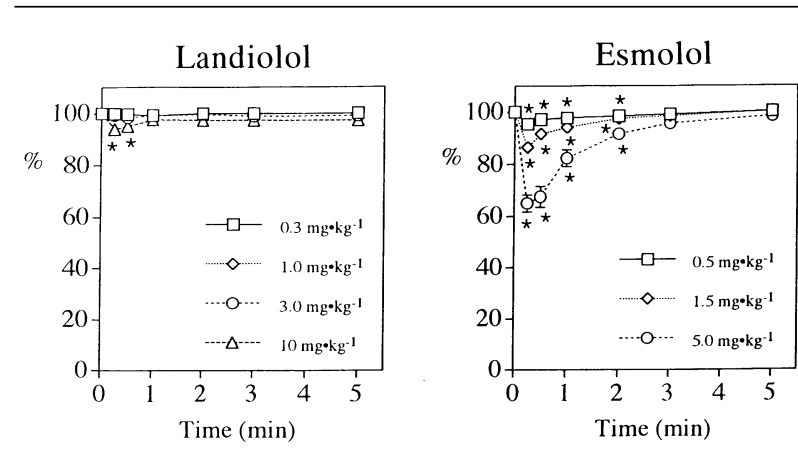

FIGURE 2 Time course of changes (\%) in mean arterial pressure (MAP) Values are mean \pm SE $(n=8) * P<0.05$ vs baseline values. Note: There were dose-dependent reductions of MAP with esmolol. MAP did not change significantly until a large dose of landiolol $\left(10 \mathrm{mg} \cdot \mathrm{kg}^{-1}\right)$ was administered.

\section{Discussion}

The main finding of the current study was that the negative chronotropic action of landiolol was slightly stronger than that of esmolol, and that landiolol did not have hypotensive effects unless a large dose was administered. Urethane was used as the anesthetic since it produces long-lasting anesthesia with minimal cardiovascular depression and it does not affect sympathetic outflow appreciably. ${ }^{13,14}$ We assume that anesthesia with urethane produced compatible physiological conditions for both landiolol and esmolol.

Perioperative tachyarrhythmias can occur unexpectedly and precipitously, and can be life-threatening.

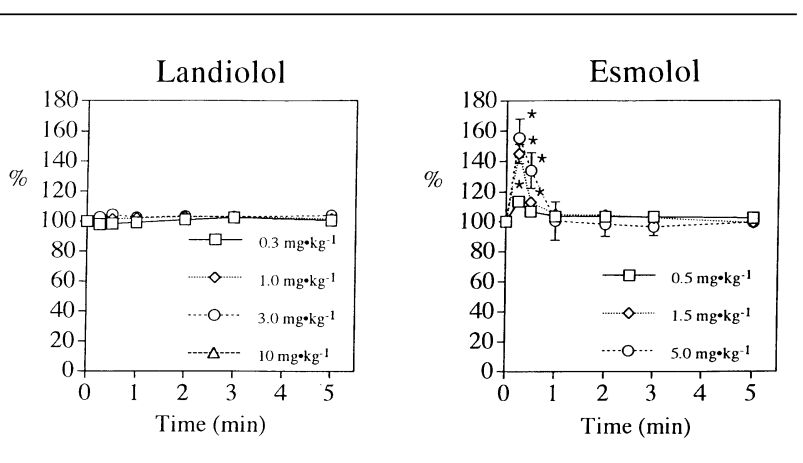

FIGURE 3 Time course of changes (\%) in renal sympathetic nerve activity (RSNA). Values are mean $\pm \operatorname{SE}(n=8) .{ }^{*} P<0.05 p$ baseline values. Note: RSNA remained unchanged with landiolol but increased in a dose-dependent fashion with esmolol.

Several $B$-adrenoceptor blockers have been used clinically to treat tachyarrhythmia. B-blockers compete with catecholamines at the $B$-adrenoceptors, thereby exerting negative chronotropic and inotropic actions. The properties of an ideal $B$-blocker should include a rapid onset of action to terminate tachyarrhythmia quickly, and a short duration of action to avoid side effects. The side effects of non-selective $\beta$-blockers include hypotension and congestive heart failure due to excessive negative inotropic action and precipitation of bronchospasm secondary to $\beta_{2}$ receptor blockade. Among $ß$-blockers, esmolol has gained popularity because of its rapid onset, short duration of action, and high cardioselectivity.

Recently, landiolol has been developed by modifying the chemical structure of esmolol in order to produce higher cardioselectivity and more potency without increasing the duration of action. According to an in vitro study, the novel, ultra-short-acting $\beta$ blocker landiolol is highly cardioselective with a $\beta_{1} / \beta_{2}$ ratio of $255 .{ }^{6}$ On the other hand, the $\beta_{1} / \beta_{2}$ ratio of esmolol is low, 33. ${ }^{6}$ Both esmolol and landiolol possess ester bonds in their chemical structure and are hydrolyzed quickly by an esterase in red blood cells, and plasma and liver esterase. ${ }^{6,14}$

There are conflicting data regarding the half-life of both agents. Iguchi et al. reported that both agents' half-life is approximately nine minutes. ${ }^{6} \mathrm{~A}$ half-life of three to four minutes was also reported with landiolol. ${ }^{15}$ In our experimental model, the bradycardic action of landiolol appears shorter than that of esmolol (Figure 1). For instance, landiolol $3 \mathrm{mg} \cdot \mathrm{kg}^{-1}$ and esmolol $5 \mathrm{mg} \cdot \mathrm{kg}^{-1}$ produced a similar reduction of 
HR; however, HR did not return to baseline value even five minutes after injection of esmolol. Thus, the half-life of landiolol may indeed be shorter than that of esmolol. Furthermore, the bradycardic action of landiolol is faster than that of esmolol (Figure 1). For instance, similar maximum reductions of HR occurred in $30 \mathrm{sec}$ with landiolol $3 \mathrm{mg} \cdot \mathrm{kg}^{-1}$ and in two minutes with esmolol $5 \mathrm{mg} \cdot \mathrm{kg}^{-1}$. The time course of changes of HR in the current study, suggest that titratability and controllability are improved with landiolol compared to esmolol.

All previous studies comparing landiolol and esmolol demonstrated that the former is a stronger $ß$ adrenoceptor blocking agent than the latter. However, the difference in potency varies from slightly more potent ${ }^{7}$ to several times more potent, ${ }^{8,9}$ to nine times more potent. ${ }^{6}$ This discrepancy can be due to different experimental models, such as an in vivo vs in vitro studies, use of different animal species and whether or not HR was increased with isoproterenol before injection of the B-blockers. Our in vivo study using rabbits indicates also that landiolol is a stronger $ß$-adrenoceptor blocking agent than esmolol since $3 \mathrm{mg} \cdot \mathrm{kg}^{-1}$ of landiolol and $5 \mathrm{mg} \cdot \mathrm{kg}^{-1}$ of esmolol produced a similar reduction of $\mathrm{HR}$. Thus, all studies comparing the two agents indicate that the therapeutic dose of landiolol to treat tachyarrhythmia is smaller than that of esmolol.

A notable finding of the current study was that arterial blood pressure remained unchanged until a fairly large dose of landiolol was administered, even though HR decreased in a dose-dependent fashion. On the other hand, arterial blood pressure decreased in a dose-dependent fashion along with the reduction of HR with esmolol (Figure 2). This suggests that landiolol possesses not only very high cardioselectivity (large $B_{1} / \beta_{2}$ ratio) but also possesses a high ratio of negative chronotropic action to negative inotropic action. Since esmolol does not affect afterload, ${ }^{9}$ decreased MAP with esmolol is likely related to its negative inotropic action. It was demonstrated in an in vivo canine model that the depressant effects of landiolol on cardiovascular performance are significantly less than those of esmolol. ${ }^{9}$ Our study also suggests that esmolol is a more potent negative inotropic agent than landiolol at equipotent bradycardic doses.

RSNA remained unchanged with stable MAP with landiolol. This indicates that landiolol likely does not suppress sympathetic nerve activity. A reflex increase in RSNA was observed with esmolol in response to the dose-dependent reduction of MAP (Figure 3 ). However, esmolol $5 \mathrm{mg} \cdot \mathrm{kg}^{-1}$ decreased RSNA in baroreceptor denervated rabbits (unpublished data,
Goto et al.). If this is the case, esmolol can exert its ßblocking action not only by competing with catecholamines at $ß$-adrenoceptor sites, but also by suppressing sympathetic outflow from the central nervous system. However, it is thought that the baroreflex-mediated increase in sympathetic nerve activity overwhelmed the direct depressant effect of esmolol on the sympathetic outflow, resulting in increases in RSNA (Figure 3).

In summary, in this rabbit model, landiolol exhibited more potent negative chronotropic effects than esmolol. Esmolol produced a dose-dependent decrease in MAP that was not observed with landiolol. Finally, in rabbits, the half-life of landiolol appears to be shorter than that of esmolol.

\section{References}

1 Gorczynski RJ. Basic pharmacology of esmolol. Am J Cardiol 1985; 56: 3F-13F.

2 Kirshenbaum JM, Kloner RA, Antman EM, Braunwald $E$. Use of an ultrashort-acting $B$-blocker in patients with acute myocardial ischemia. Circulation 1985; 72 : $873-80$.

3 Jacobs JR, Maier GW, Rankin JS, Reves JG. Esmolol and left ventricular function in the awake dog. Anesthesiology 1988; 68: 373-8.

4 Murthy VS, Hwang TF, Zagar ME, Vollmer RR, Schmidt DH. Cardiovascular pharmacology of ASL8052 , an ultra-short acting B-blocker. Eur J Pharmacol 1983; 94: 43-51.

5 Reilly CS, Wood M, Koshakji RP, Wood AJJ. Ultrashort-acting beta-blockade: a comparison with conven tional beta-blockade. Clin Pharmacol Ther 1985; 38: $579-85$.

6 Iguchi S, Iwamura $H$, Nishizaki $M$, et al. Developmen of a highly cardioselective ultrashort-acting $ß$ - blocker, ONO-1101. Chem Pharm Bull 1992; 40: 1462-9.

7 Motomura S, Hagihara A, Narumi $\Upsilon$, Hashimoto K. Time course of a new ultrashort-acting $B$ - adrenoceptor-blocking drug, ONO-1101: comparison with those of esmolol and propranolol by using the canine isolated, blood-perfused heart preparations. J Cardiovasc Pharmacol 1998; 31: 431-40.

8 Muraki K, Nakagawa H, Nagano N, et al. Effects of ONO-1101, a novel beta-antagonist, on action potential and membrane currents in cardiac muscle. J Pharmacol Exper Ther 1996; 278: 555-63.

9 Sugivama A, Takahara A, Hashimoto $K$ Electrophysiologic, cardiohemodynamic and $B$-blocking actions of a new ultra-short-acting $B$-blocker, ONO-1101, assessed by the in vivo canine model in comparison with esmolol. J Cardiovasc Pharmacol 1999; 34: 70-7. 
10 Taneyama C, Goto H, Goto K, Benson KT, Unrub GK, Arakawa K. Attenuation of arterial baroreceptor reflex response to acute hypovolemia during induced hypotension. Anesthesiology 1990; 73: 433-40

11 Shinohara K, Aono H, Unruh GK, Kindscher JD, Goto $H$. Suppressive effects of remifentanil on hemodynamics in baro-denervated rabbits. Can J Anesth 2000; 47: 361-6.

12 Ishikawa N, Kallman CH, Sagawa K. Rabbit carotid sinus reflex under pentobarbital, urethane, and chloralose anesthesia. Am J Physiol 1984; 246: H696-701.

13 Matsukawa K, Ninomiya I. Anesthetic effects on tonic and reflex renal sympathetic nerve activity in awake cats. Am J Physiol 1989; 256: R371-8.

14 Erbardt PW, Woo CM, Anderson WG, Gorczynski RJ. Ultra-short-acting $B$-adrenergic receptor blocking agents. 2. (Aryloxy) propranolamines containing esters on the aryl function. J Med Chem 1982; 25: 1408-12.

15 Kitamura A, Sakamoto A, Inoue T, Ogawa R. Efficacy of an ultrashort-acting $B$-adrenoceptor blocker $(\mathrm{ONO}$ $1101)$ in attenuating cardiovascular responses to endotracheal intubation. Eur J Clin Pharmacol 1997; 51: $467-71$. 